\title{
Nota Técnica: \\ Líquenes como posibles agentes de deterioro de areniscas en las ruinas jesuíticas de San Ignacio Miní (provincia de Misiones, Argentina)
}

\author{
Technical Note: \\ Lichens as possible agents of sandstone deterioration in Jesuitic ruins \\ of San Ignacio Miní (Misiones Province, Argentina)
}

\author{
$\underline{\text { V. G. Rosato }}^{*}$ )
}

Recepción/Received: 6-III-09

Aceptación/Accepted: 22-IV-09

Publicado online/Online publishing: 11-VIII-10

\section{RESUMEN}

Incluidas en la lista de Patrimonio Mundial por la UNES$\mathrm{CO}$, las ruinas de San Ignacio Miní, en el NE de Argentina, provincia de Misiones, fueron construidas en el siglo XVIII por pobladores guaraníes supervisados por la Compañía de Jesús. Las ruinas se encuentran en una zona de clima tropical, expuestas a condiciones extremas de calor y humedad que alteran a las rocas empleadas en su construcción. Estas rocas se identifican como areniscas silíceas, formadas por clastos redondeados a sub-redondeados, con escasas partículas angulosas, con un contenido de $96,0 \%$ cuarzo.

Las características del clima favorecen el desarrollo tanto de plantas vasculares como también de musgos, algas y otros organismos capaces de dañar a los materiales. Entre éstos se incluyen 18 especies de líquenes (pertenecientes a 18 géneros), 8 foliosos, 3 fruticosos y 7 crustosos. Las observaciones con SEM y los microanálisis EDE de muestras de roca colonizadas por Caloplaca $s p$. y Buellia $s p$ sugieren que estos líquenes ejercen una acción negativa sobre la roca.

Palabras clave: areniscas, líquenes, estudios con MEB y EDAX, ensayo de caracterización, provincia de Misiones. Argentina.

\section{SUMMARY}

The ruins of San Ignacio Miní, in NE Argentina, Misiones Province, included by the UNESCO in the list of World Heritage in 1984, were built in the $18^{\text {th }}$ century by the Guarani people under the supervision of the Jesuite Congregation. The ruins are located in a tropical weather zone, exposed to extreme conditions of heat and humidity affecting the rocks used in its construction. These rocks are identified as siliceous sandstones, mainly formed by rounded to subrounded clasts, with scarce angulose particles, containing $96 \%$ quartz.

Weather characteristics encourage the growth of vascular plants as well as algae and mosses and other organisms that damage materials. Among these, there are 18 lichen species (belonging to 18 genera), 8 foliose, 3 fruticose and 7 crustose. The damaging action of these lichens has been observed through SEM observations and EDAX microanalysis of rock samples colonized by Caloplaca sp. and Buellia sp.

Keywords: sandstone, lichens, SEM EDAX studies, characteristic tests, Misiones Province. Argentina.

(*) LEMIT (La Plata, Argentina).

Persona de contacto/Corresponding author: direccion@lemit.gov.ar 


\section{INTRODUCCIÓN}

Fundada en 1610 por los padres José Cataldino y Simón Maceta, la misión jesuítica de San Ignacio en la provincia de Misiones, Argentina, es uno de los mayores exponentes de la arquitectura nacida de la fusión del arte religioso del barroco español con la sensibilidad y la espontaneidad del arte guaraní.

Luego de la expulsión de los jesuitas en 1776, la ciudad sobrevivió hasta su destrucción en 1817 durante la guerra de fronteras entre los Estados de la región. Restaurada entre 1940-1950, San Ignacio es tal vez el ejemplo mejor conservado del arte jesuítico en Argentina y está listada entre los Monumentos Históricos Nacionales. En 1984, la UNESCO las incluyó en la lista del Patrimonio Mundial (1).

En 2007 se realizó la limpieza de la entrada principal del Templo Mayor. Primero se eliminaron las plantas vasculares, luego se limpiaron las superficies, primero con un cepillado suave a seco y luego empleando una técnica definida experimentalmente con la realización de ensayos: la superficie se humedeció con un bactericida seguido por una limpieza mecánica por medio de cepillos y enjuagando con agua. Las piedras flojas se afirmaron y las faltantes fueron reemplazadas para mantener la seguridad estructural. Los lugares por donde pudiera escurrir o estancarse el agua de lluvia se trataron con un hidrofugante (mezcla de silano y siloxano en base acuosa) (2).

Razones históricas y artísticas justifican la necesidad de conservar este patrimonio ubicado en una zona tropical y, por lo tanto, expuesto a las extremas condiciones de calor y humedad que afectan a los materiales de construcción, en particular las rocas. Estos factores climáticos permiten el desarrollo de vegetación selvática con una acción negativa sobre el monumento, causada por el crecimiento de plantas vasculares (helechos, hierbas, enredaderas) y otros organismos figurasintéticos (líquenes y musgos). Sin embargo, la cubierta de líquenes podría tener acción protectora contra el deterioro. Esto se observó, por ejemplo, en templos de arenisca en Tailandia (3), en un ambiente con clima y vegetación similares a los de las misiones. También se ha informado acerca del efecto bioprotector de la asociación de cianobacterias y el alga verde Gloeocystis rupestris con el hongo Septonema tormes sobre la arenisca de Villamayor que cubre la Casa Lis de Salamanca, España (4).

Por su parte, Wessels y Schoeman estimaron para las areniscas de Clarens, Sudáfrica, que una colonia de un liquen que identificaron como Lecidea aff. sarcogynoides deteriora un valor promedio estimado de
9,6 mm cada 100 años (5). Pero ésta es una especie endolítica (que crece dentro de la roca), diferente a las otras mencionadas anteriormente, con un modo de vida epilítico (que crecen en la superficie), lo que puede explicar la diferente acción ejercida sobre el sustrato.

El objetivo de este trabajo es caracterizar mineralógica y tecnológicamente las rocas de las misiones jesuíticas, proveer información sobre las características petrográficas de las rocas empleadas en su construcción, identificar las especies de líquenes que colonizan las ruinas de las misiones jesuíticas de San Ignacio, el lugar y exposición donde se recolectaron, y el posible rol de estos organismos en el deterioro de las rocas.

\section{MATERIALES Y MÉTODOS}

\subsection{Descripción de la zona de estudio}

\section{Descripción del monumento}

La distribución de los edificios de las misiones se organizaba alrededor de la plaza y estaba dominado por el grupo formado por el Cabildo (Ayuntamiento) y el Templo Mayor, con baptisterio y sacristía. A uno de los lados se encontraba la casa de los sacerdotes, la escuela, el refectorio, el taller y los almacenes, enfrentados con el cementerio, la huerta y el coty-guazú (casa para viudas y huérfanos).

Las casas de los pobladores guaraníes, con doble galería, completaban los límites de la plaza. La entrada principal desde el norte era una calle central con la perspectiva enfocada en la fachada del templo, mostrando la concepción barroca usada para organizar a las misiones. El Templo Mayor, con tres naves, se construyó con mampostería de rocas (arenisca de color rojo obtenida de canteras de la zona) ajustada sin mortero. El techo estaba cubierto con tejas, con doble agua y apoyado en una estructura de madera. En los principales sectores del templo, como el portal de entrada, la sacristía y la conexión del templo con la escuela, se destacan los diseños tallados en las piedras. En las figuras de ángeles, palomas y diseños tomados de la flora local, se aprecian las características guaraníes. El diseño de otros elementos arquitectónicos como pisos y balaustradas resulta de gran interés (1).

La Figura 1 es una vista aérea obtenida de Google Earth, que da una idea general de la distribución de los edificios. 


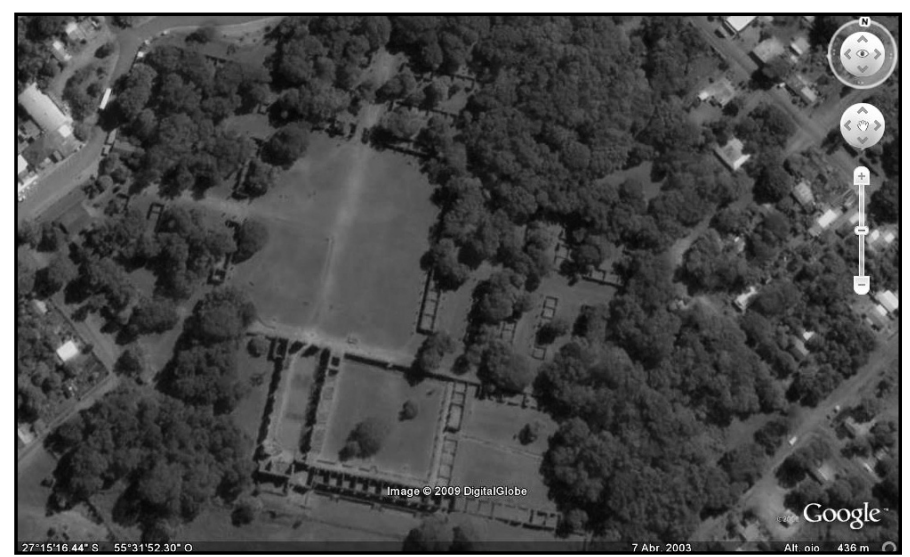

Figura 1. Vista aérea de la misión jesuítica (tomado de Google Earth).

\section{Climatología}

Los datos para caracterizar el clima de la región se obtuvieron en la Estación Climatológica del Aeropuerto de Posadas perteneciente al Servicio Meteorológico Nacional de la Fuerza Aérea Argentina, a $60 \mathrm{~km}$ de las ruinas (periodo 1971/1980).

El clima de la zona es subtropical sin estación seca. La temperatura anual promedio es $21,2{ }^{\circ} \mathrm{C}$, las medias mensuales más altas se dan en diciembre, enero y febrero con $25,4,26,3$ y $25,9{ }^{\circ} \mathrm{C}$ respectivamente y las más bajas en junio, julio y agosto con $16,1,16,6$ y $16,8{ }^{\circ} \mathrm{C}$ respectivamente.

La precipitación media anual es de $1.604 \mathrm{~mm}$, con los mayores promedios mensuales en octubre, diciembre $y$ enero con 161,168 y 154 mm, respectivamente, mientras el promedio mensual más bajo se da en julio con 92 $\mathrm{mm}$.

El promedio anual de humedad relativa es $74 \%$, con los valores mensuales promedios más altos de $79 \%$ en mayo y junio y los más bajos de $70 \%$ en octubre.

\subsection{Estudios biológicos, mineralógicos y tecnológicos realizados}

Los líquenes se muestrearon sin dañar el sustrato, separándolos con la mano o con un bisturí para evitar dañar el monumento. Los líquenes crustosos que se informan se recibieron en el LEMIT (Laboratorio de Entrenamiento Multidisciplinario para la Investigación Tecnológica) para su identificación. Los líquenes se observaron bajo microscopio estereoscópico y óptico y se determinaron con claves (6-12). También se realizaron observaciones de líquenes y sustrato con MEB (microscopio electrónico de barrido) y microanálisis EDE (espectrometría de dispersión de electrones) mediante la sonda EDAX.
Sobre las muestras de rocas se realizaron cortes delgados y estudios petrográficos y tecnológicos.

La densidad se midió en condiciones saturadas y superficie seca y la absorción de agua como medida de la porosidad se ensayó por inmersión durante 24 horas tomando lecturas a intervalos crecientes de tiempo. Luego se determinó la pérdida de agua de muestras saturadas expuestas a diferentes humedades relativas (95\% y $50 \%$ ). Este ensayo fue realizado para comprobar si la roca se seca o retiene agua en su red de poros y capilares luego de un proceso de humedecimiento por lluvia.

La resistencia a compresión en las direcciones de los planos de delaminación sedimentaria formados durante la deposición de los sedimentos se ensayó en cilindros de $2,5 \mathrm{~cm}$ de diámetro y relación de esbeltez $=2$. En forma complementaria se evaluaron muestras en condición saturada y superficie seca. Estos ensayos se realizaron en una máquina Instron modelo 44-83 con una capacidad máxima de 15 toneladas y con una velocidad de 0,3 $\mathrm{mm} / \mathrm{min}$.

También se midió la resistencia al desgaste superficial (ensayo de abrasión con máquina Dorry) como factor que puede indicar la alterabilidad superficial causada por las colonias biológicas.

\section{RESULTADOS}

\subsection{Estudios petrográficos y tecnológicos de las rocas}

Las rocas areniscas usadas en San Ignacio Miní pertenecen al lecho Curuzú Cuatiá del Cretácico Inferior. Estas areniscas aparecen en el substrato de basalto o bien están insertas entre las diferentes coladas volcánicas. 
Se reconocen dos tipos fundamentales (13): la primera tiene características cuarcíticas, en algunos casos se vuelven verdaderas cuarcitas con color rojizo a amarillento pálido, en general no están expuestas en grandes lechos. El otro tipo, que es el usado en la construcción de las misiones, tiene menor consistencia, grano ligeramente más grueso que el anterior y un color pálido rojizo, debido a la presencia de hierro en su composición. En general estas areniscas varían de friables a compactas y se presentan escasamente cementadas.

Las características petrográficas de las rocas indican que están formadas principalmente por clastos redondeados a subredondeados, con escasas partículas angulosas. El cemento es de naturaleza silícea, con presencia de ópalo y limoarcilloso con impregnaciones ferruginosas de hematita (Figura 2).

Mineralógicamente están formadas por 96,0\% cuarzo, principalmente clastos con extinción homogénea, con sólo $1 \%$ de cuarzo con extinción ligeramente a moderadamente ondulante. Les siguen en abundancia los fragmentos de roca basáltica con 1,5\%, de feldespatos ligeramente alterados con $1,0 \%$ de minerales opacos principalmente magnetita alterada con hematita, y al menos $0,5 \%$ de zirconio. En la sección delgada se nota que la roca es porosa (Figura 3).

Para evaluar tecnológicamente el comportamiento de las rocas, en especial los aspectos vinculados con su

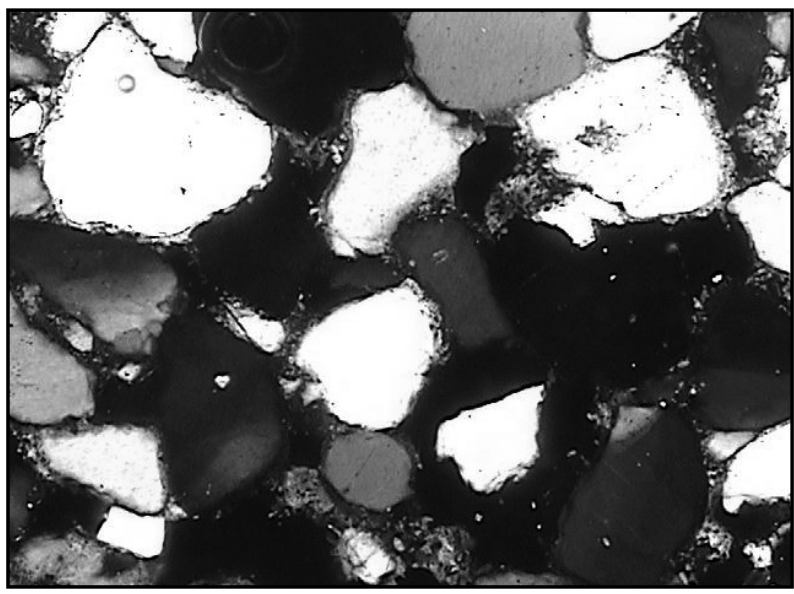

Figura 2. Corte delgado de arenisca de las misiones visto en microscopio con contraste de fases. comportamiento durable, se realizaron ensayos físicos y mecánicos.

Los resultados de densidad y absorción se presentan en la Tabla 1. Los títulos de la tabla indican: $\bar{x}$, los valores medios; s, la desviación estándar y $n$, el número de ensayos. También se presenta la curva de absorción de agua y la curva de retención de agua. Se observa que la roca llega casi al nivel de saturación ya a las 2 horas. Por otra parte, en condiciones de poca humedad, la roca pierde agua rápidamente. Aunque el clima en la zona de las misiones jesuíticas es húmedo, cabe esperar que en las rocas expuestas al sol tenga lugar este proceso de secado.

Debe mencionarse que determinaciones realizadas sobre muestras que se observaban alteradas a simple vista se obtienen valores de densidad del orden de 2,11 y absorciones de agua en 24 horas de 5,2. Esta situación indica la variabilidad de las características de las rocas que conforman las ruinas de la misión y el grado de deterioro que pueden alcanzar según el lugar de exposición.

Los valores de resistencia a compresión obtenidos ( $f^{\prime} c=720 \pm 80 \mathrm{~kg} / \mathrm{cm}^{2}$ ) muestran que la estratificación por sedimentación es muy leve y no influye en el comportamiento mecánico de la roca. Por lo tanto, la estratificación no genera debilidades según el plano de sedimentación, pudiéndose plantear que la roca

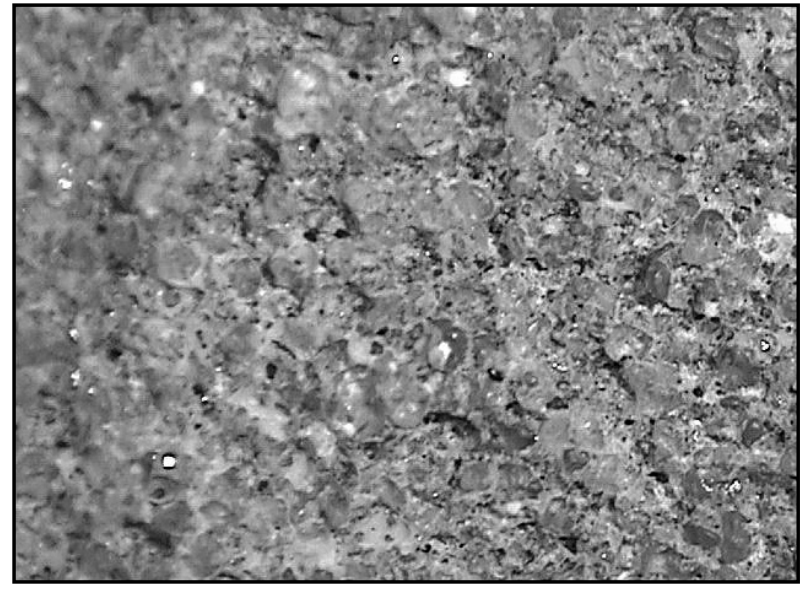

Figura 3. Corte delgado de arenisca de las misiones visto en microscopio con luz normal.

Tabla 1. Ensayos tecnológicos ( $\overline{\mathrm{x}}$ : promedio, s: desviación estándar, N: número de ensayos).

\begin{tabular}{|c|c|c|c|c|c|c|c|c|}
\hline \multicolumn{2}{|c|}{ Densidad (saturada y superficie seca) } & \multicolumn{3}{|c|}{ Absorción de agua en 24 $\mathbf{h}$ (\%) } & \multicolumn{3}{|c|}{ Porosidad (1) (\%) } \\
\hline$\overline{\mathbf{x}}$ & $\mathbf{S}$ & $\mathbf{N}$ & $\overline{\mathbf{x}}$ & $\mathbf{S}$ & $\mathbf{n}$ & $\overline{\mathbf{x}}$ & $\mathbf{S}$ & $\mathbf{n}$ \\
\hline 2,45 & 0,01 & 3 & 3,23 & 0,57 & 5 & 11,4 & 0,4 & 3 \\
\hline
\end{tabular}

(1) Porosidad definida como la relación entre la densidad de la muestra y la densidad de la muestra triturada a paso tamiz 200. 


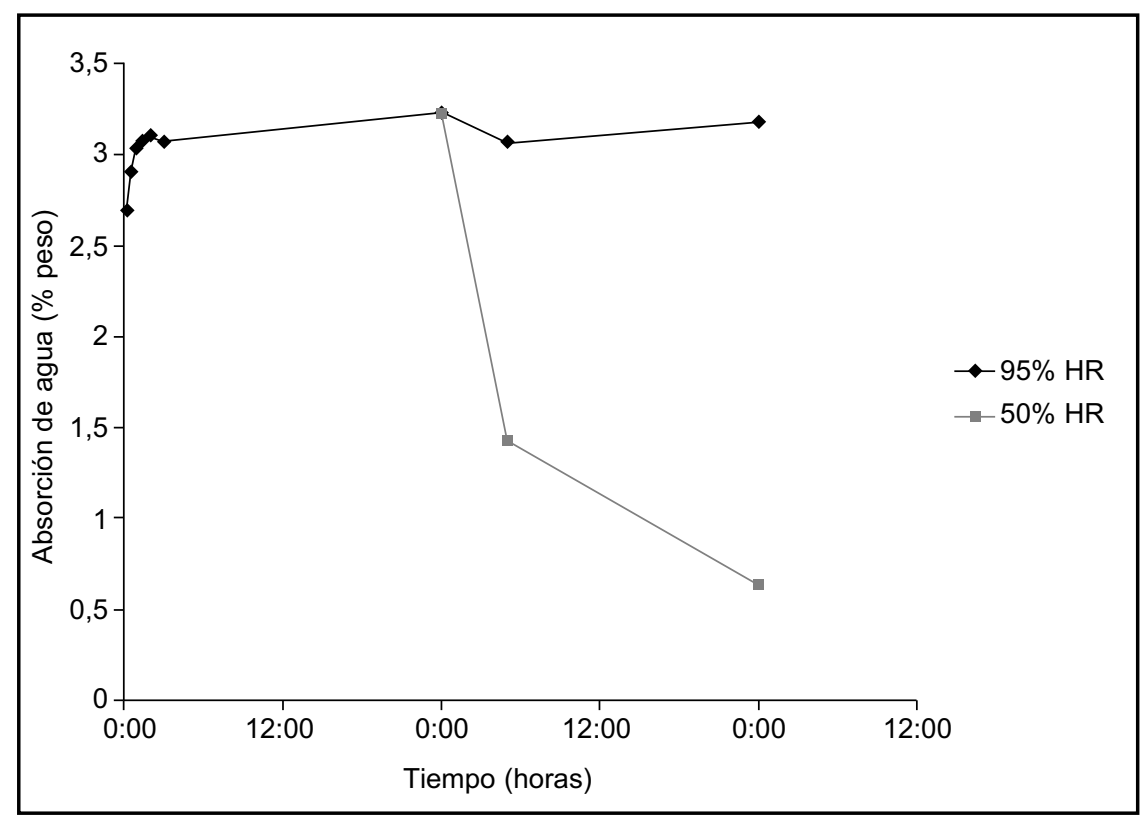

Figura 4. Curva de absorción y retención de agua a 24 horas.

presenta anisotropía desde el punto de vista estructural. Tampoco se observaron diferencias en la resistencia entre las muestras secas y saturadas.

Con respecto al ensayo de resistencia a la abrasión, el comportamiento de las rocas se cuantificó midiendo la pérdida de altura sobre lecho de arena de las muestras en metros a los 100, 300, 500, 700 y 1.000 m de distancia, con una carga de $250 \mathrm{~g} / \mathrm{cm}^{2}$. Los resultados obtenidos indican altos valores de abrasión para todas las muestras. Se observa que la pérdida es mayor en la roca con liquen, lo que indica una mayor fragilidad de la superficie. El desgaste de la muestra con liquen es mayor al comienzo y luego las líneas se hacen paralelas, lo que demuestra que la superficie colonizada es más débil.

\subsection{Especies de líquenes halladas}

Uno de los problemas principales y de mayor riesgo para las construcciones que integran las misiones es el crecimiento de plantas entre las rocas que conforman sus muros. Las raíces penetran entre las piedras y ejercen presión, separándolas y provocando fisuras e incluso la caída de las piedras, que en casos extremos pueden hacer colapsar el muro.

Además de las plantas, también hay que considerar que los líquenes pueden deteriorar las superficies de las areniscas (Figura 6). En la misión de San Ignacio se identificaron 18 especies pertenecientes a 11 géneros diferentes. Las especies, los lugares donde se hallaron y sus preferencias por el sol o la sombra se muestran en la Tabla 2.

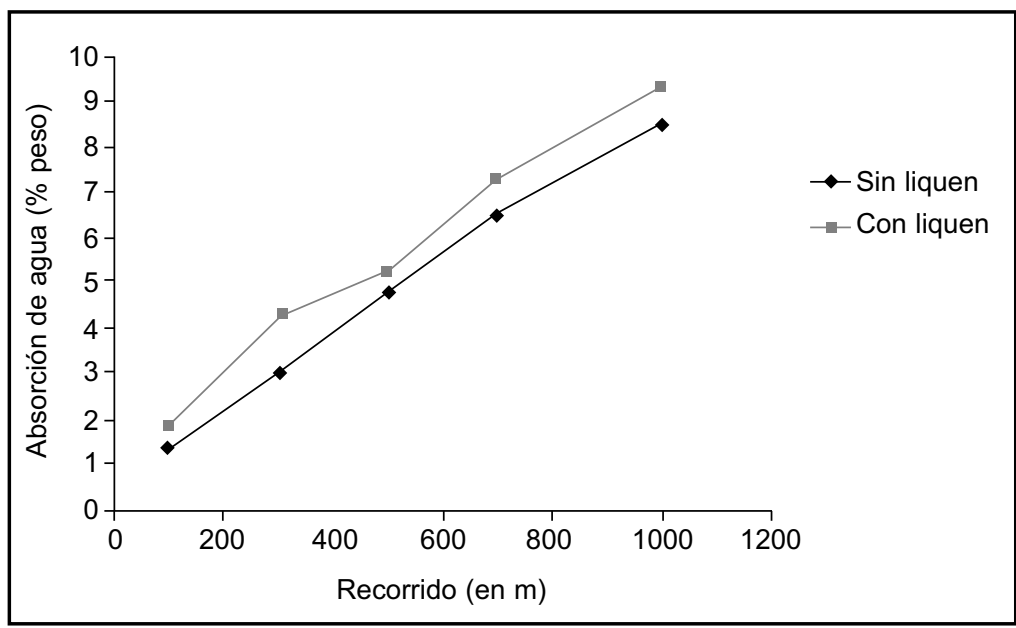

Figura 5. Datos del ensayo de abrasión de las caras no colonizadas y colonizada de una laja de arenisca del piso de las misiones. 


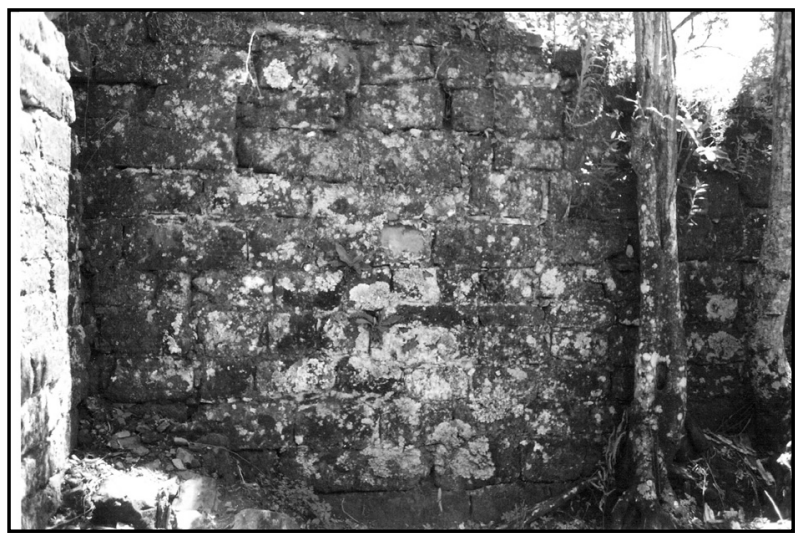

Figura 6. Pared de la casa junto a la capilla cubierta de líquenes.

Tabla 2. Especies de líquenes halladas en las ruinas de la misión jesuítica y estructuras colonizadas.

\begin{tabular}{|c|c|c|c|}
\hline Especies & Elemento & Sol & Sombra \\
\hline Parmotrema austrosinensis & Pared de una casa junto a la capilla, sobre arenisca & $\mathrm{X}$ \\
\hline Hypotrachyna osorioi & Pared de una casa junto a la capilla, sobre arenisca & $\mathrm{X}$ \\
\hline Pyxine endoleuca & Pilar, arenisca & $\mathrm{X}$ \\
\hline Cladonia bellidiflora & Pilar, arenisca & $\mathrm{X}$ \\
\hline Heterodermia diademata & Pared de una casa junto a la capilla, sobre arenisca & $\mathrm{X}$ \\
\hline Sticta weigelii & Pared de una casa junto a la capilla, sobre arenisca & $\mathrm{X}$ \\
\hline Rimelia diffracta & Pared de una casa junto a la capilla, sobre arenisca & $\mathrm{X}$ \\
\hline Ramalina celastrii & Sobre columna de arenisca, frente al Cabildo & $\mathrm{X}$ \\
\hline Usnea subglaucescens & Sobre columna de arenisca, frente al Cabildo & $\mathrm{X}$ \\
\hline Lepraria sp. & Sobre arenisca & $\mathrm{X}$ \\
\hline Cladonia fimbriata & Sobre roca expuesta al sol & $\mathrm{X}$ & \\
\hline
\end{tabular}

Entre los especímenes traídos al LEMIT para ser identificados se verifica la exstencia de cinco especies crustosas: Buellia aff. conspirans, Catillaria sp,; Caloplaca irrubescens and Diploschistes sp. Otras dos especies foliosas se identificaron como: Parmotrema chinense y Punctelia punctilla. Desafortunadamente no hay datos sobre la ubicación exacta de estas muestras y su exposición o no al sol y la lluvia.
También se verifica la existencia de algas verdes (Ulothrix) y cianobacterias (Aphanocapsa $s p ;$ Xenococcus $s p$; Tolypothrix $s p$ y otro espécimen de la familia Borzinemataceae, orden Stigonematales) que se encontraron en una muestra de una laja del piso. En la Figura 7 se observa el crecimiento superficial de estos organismos.

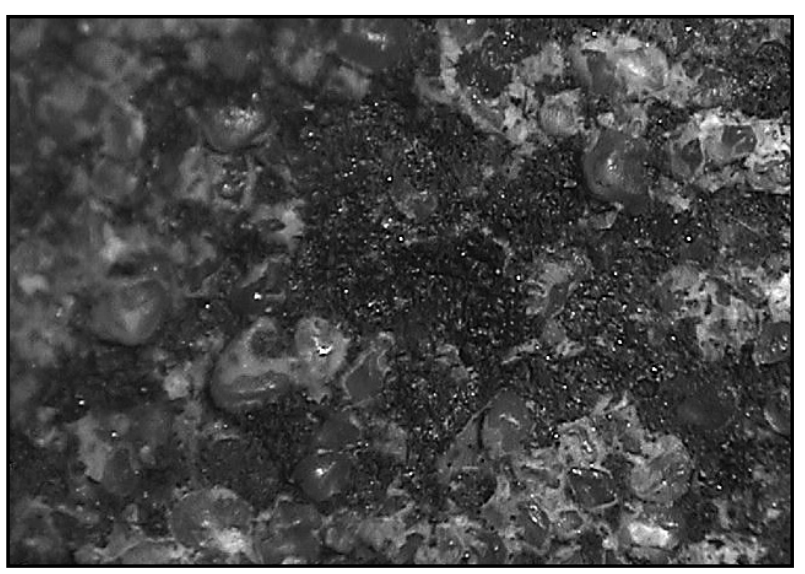

Figura 7. Vista superficial de la roca con crecimientos de algas. 
Muestras de rocas colonizadas por Caloplaca sp y Buellia $s p$ se observaron con MEB. En las rocas atacadas por Buellia $s p$. la superficie está alveolada, mientras Caloplaca $s p$ sólo produce canales de perforación (Figuras 8, 9, 10 y 11$)$.

Se efectuaron microanálisis EDE (Tabla 3) y se observó que no hay diferencias importantes de composición química entre rocas atacadas y no atacada, excepto un mayor contenido de aluminio. Esto sugiere que los líquenes estudiados (Buellia aff. conspirans y Caloplaca

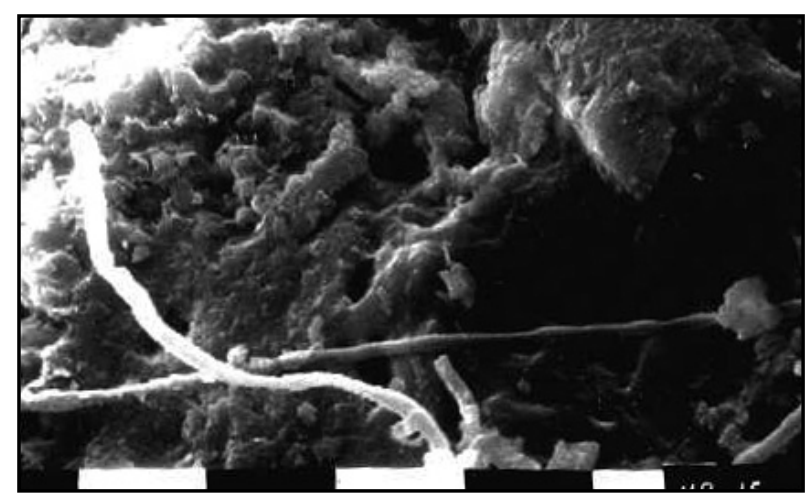

Figura 8. Fotomicrografía MEB de Caloplaca sp.: nótese el liquen creciendo alrededor de un clasto de la roca.

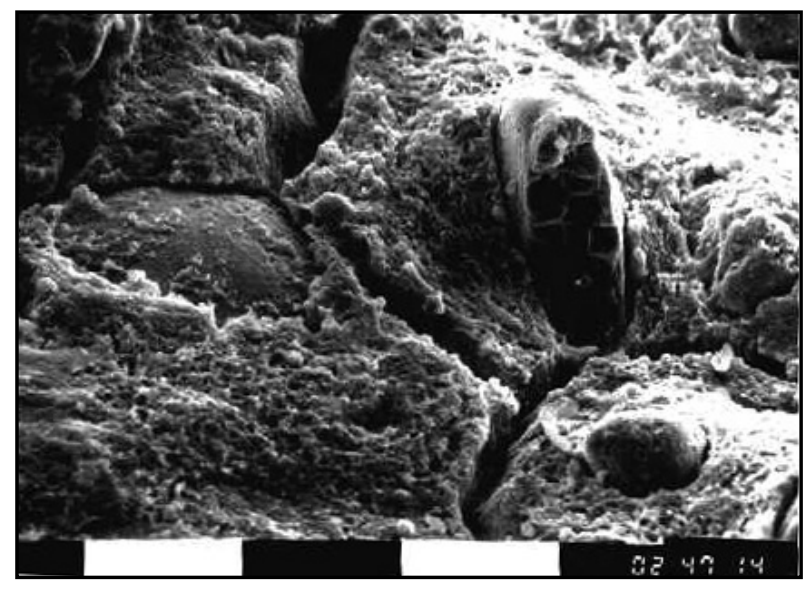

Figura 10. Fotomicrografía MEB de Buellia sp. Nótese el liquen penetrando la roca. irrubescens) pueden inducir la concentración de este elemento, pero se necesitan nuevos estudios para comprobarlo.

\section{Discusión}

Entre las especies de líquenes halladas, se observa la presencia de Sticta weigelii, una especie común en la zona con amplia distribución, fue citada por Malme de Paraguay (12), mientras Osorio (14-18) la menciona en Misiones, y también en Brasil (R. Grande do Sul) y Uruguay.

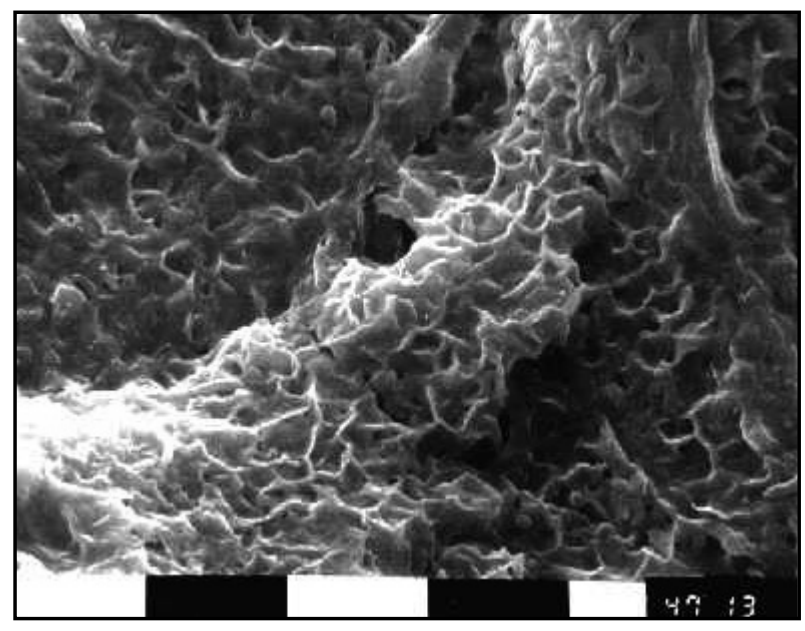

Figura 9. "Macerado" de una muestra de roca colonizada por Caloplaca sp.

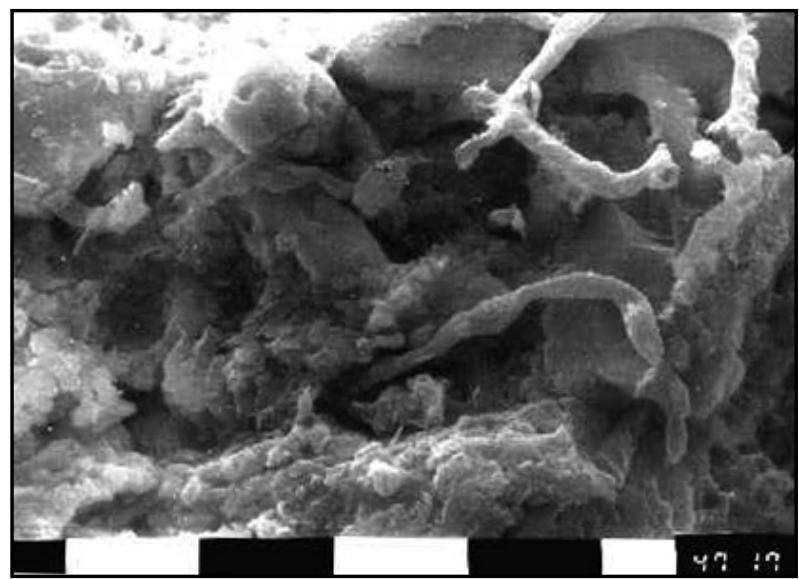

Figura 11. Fotomicrografía MEB de Buellia sp. Detalle de una hifa y roca perforada por canales.

Tabla 3. Resultados de los microanálisis EDE.

\begin{tabular}{|c|c|c|c|c|c|}
\hline Tipo de roca & Al & Si & K & Ca & Fe \\
\hline Roca no colonizada & 6,25 & 86,58 & - & 1,4 & 5,77 \\
\hline Roca colonizada por Caloplaca $s p$ & 14,9 & 73,02 & 4,28 & 1,18 & 6,52 \\
\hline Roca colonizada por Buellia $s p$ & 12,44 & 84,43 & - & - & 3,13 \\
\hline
\end{tabular}


Por el otro lado, Cladonia bellidiflora, C. fimbriata, Rimelia diffracta, Hypotrachina osorioi y Parmotrema austrosinensis no se mencionan previamente en la provincia de Misiones. En San Ignacio también hay líquenes crustosos, como Caloplaca irrubescens y Buellia aff. conspirans.

Las diferencias de morfología y hábito (forma de crecimiento) de los líquenes son importantes en lo relacionado con las alteraciones, porque influencian la relación liquen-sustrato. Los líquenes foliosos pueden causar un mayor daño estético debido a su tamaño, pero sólo causan daño por acción mecánica en los lugares donde penetran los ricines, particularmente en rocas porosas, como en el caso de las areniscas en estudio. Por otro lado, los líquenes crustosos se adhieren al sustrato por su cara inferior, y afectan toda la superficie que ocupan deteriorándola por acción mecánica y también por acción química debida a los ácidos orgánicos que secretan.

Puesto que las especies estudiadas son epilíticas, como los líquenes observados en los templos de Tailandia (3) o la Casa Lis (4), cabe pensar que ejerzan una acción protectora sobre la roca, pero los resultados de los ensayos de resistencia a la abrasión y las observaciones con MEB no apoyan esta hipótesis. En verdad, estas especies parecen actuar de modo más semejante a Lecidea aff. sarcogynoides, una especie que causa deterioro de las areniscas (5). Sin embargo, a diferencia de esta especie endolítica de Sudáfrica, los líquenes hallados en las misiones jesuíticas sólo afectan un estrato superficial muy delgado.

\section{CONCLUSIONES}

La superficie de las muestras de rocas pertenecientes a la misión San Ignacio Miní se encuentra alterada, debido a la pérdida de parte del cemento limoso-arcilloso con impregnaciones ferrugíneas, arrastrado por el agua de lluvia y la acción mecánica de los crecimientos biológicos. Estos procesos llevan al aumento de la porosidad de la roca y la absorción de agua, tornándolas más friables que la roca recién extraída de la cantera. Por lo demás, es una roca de tipo compacta y los planos de delaminación no influyen en la resistencia a compresión, que tampoco varía si la roca está seca o en condición saturada.

Las condiciones del clima de la zona, de tipo húmedo subtropical, originan un mayor deterioro cuando las rocas están expuestas, siendo los procesos de degradación acumulativos en el tiempo.
En total se registraron 18 especies de líquenes. Once especies se hallaron colonizando los muros, especialmente los de las casas junto a la capilla y las columnas del frente del Cabildo con notable preferencia por los lugares sombríos. Esto se atribuye a las características de las rocas, que absorben humedad con rapidez, pero que no retienen el agua. Éste parece el motivo más probable por el que los líquenes se desarrollan en los sitios sombríos, donde el sol no puede evaporar el agua de lluvia absorbida por la roca. No hay colonias destacables en el Templo Mayor excepto la presencia de algunos líquenes crustosos que no pudieron muestrearse.

Las diferentes morfologías de los líquenes estudiados están representadas como sigue: ocho especies son foliosas, tres son fruticosas y el resto crustosas. Aunque estos líquenes tienen gran tamaño y ocupan superficies bastante amplias se debe considerar que se encuentran limitados a edificios específicos del complejo de la antigua misión.

Debe también considerarse que estos líquenes probablemente están evitando la degradación (meteorización) de la roca, formando una cubierta continua al proteger las superficies contra el efecto de lluvias y otros factores climáticos, particularmente perjudiciales para las rocas blandas como son las usadas para construir la misión. Sin embargo, las observaciones con microscopio óptico, MEB y los ensayos de desgaste Dorry indican que los líquenes efectivamente ocasionan alteraciones en la capa superficial de la piedra.

La preservación de la roca por consolidación y la colocación de hidrofugantes puede ser una alternativa para su protección, tomando en cuenta los recaudos y los estudios necesarios para asegurar el resultado esperado (tal como se hizo en la restauración de 2007), sobre todo en vista de la importante alteración sufrida por la piedra durante los 330 años en que estuvo expuesta a condiciones de un medio ambiente conformado por temperatura y humedad.

\section{AGRADECIMIENTOS}

A la Administración de Parques Nacionales por el permiso para muestrear en el P.N. Iguazú y otras áreas de reserva de la provincia de Misiones. Al personal del LEMIT por la ayuda en la realización de los distintos ensayos requeridos.

\section{BIBLIOGRAFÍA}

(1) Comisión Nacional de Museos y Monumentos Históricos: Monumentos históricos de la República Argentina, pp. 55-56, Ediciones de Arte Gaglianone, Buenos Aires, (1998), véase también www.monumentos.org.ar/08mis/mis004.htm 
(2) Equipo editorial de la revista Hábitat: "Misión jesuítico-guaraní de San Ignacio Miní. Restauración de la portada principal de la Iglesia. Finalización del proyecto". Habitat, año XIV, no 56 (2008), pp. 30-35.

(3) Wendler, E.; Prasarset, C.: "Lichen growth on Old Khmer styled sandstone monuments in Thailand: Damage factor or shelter?". Preprints: 12th. Triennal meeting of the ICOM Commitee for Conservation (29 de agosto y 3 de septiembre de 1999), Lyon, pp. 759-754.

(4) Grondona, I.; Monte, E.; Rives, V.; Vicente, M. A.: "Lichenized association between Septonema tormes sp. Nov.; a coccoid cyanobacterium and a green alga with an unforeseen biopreservation effect of Villamayor sandstone at 'Casa Lis' of Salamanca, Spain". Mycological Research, vol. 108, no 12 (1997), pp. 1489-1495.

(5) Wessels, D. C. J.; Schoeman, P.: "Mechanism and rate of weathering of Clarens sandstone by an endolithic lichen". South African Journal of Science, vol. 84, no 4 (1988), pp. 274-277.

(6) Ferraro, L. I.: "Contribución a la flora liquenológica de Corrientes (Argentina)". FACENA, vol. 2 (1978), pp. 167-244.

(7) Ferraro, L. I.: "Contribución al estudio de las Parmeliáceas (líquenes) de Corrientes, Rep. Argentina". Bonplandia, vol. 5, no 12 (1981), pp. 83-99.

(8) Adler, M.: "Clave de Parmeliaceae de la provincia de Buenos Aires". Boletín Sociedad Argentina de Botánica, vol. 28, no 1-2 (1992), pp. 11-17.

(9) Scutari, N. C.: "Estudios sobre Pyxinaceae foliosas (Lecanorales, Ascomycotina) de la Argentina IV: Clave de los géneros y las especies de la provincia de Buenos Aires". Boletín Sociedad Argentina de Botánica, vol. 28, no 1-2 (1992), pp. 169-173.

(10) Galloway, D. J.: "Studies on the lichen genus Sticta (Schreber) Ach.: I. Southern South American species". Lichenologist, vol. 26, no 3 (1994), pp. 223-282.

(11) Malme, G. O.: "Die Ramalinen der Ersten Regnellschen Expedition". Ark. f. Bot.; vol. XXVI A, no 13 (1934), pp. 1-10.

(12) Malme, G. O.: "Die Stictazeen der Ersten Regnellschen Expedition". Ark. f. Bot;; vol. XXVI A, no 14 (1934), pp. 1-18.

(13) Cortelezzi, C. R.; Colado, U.; Muñoz, L.: "Disyunción columnar en areniscas mesozoicas (Formación Misiones) República del Paraguay". Notas del Museo de La Plata XXI, Geología, no 76 (1988), pp. 170-176.

(14) Osorio, H. S.: "Contributions to the lichen flora of Argentina, II: Lichens from the Province of Misiones". Comunic. Bot. Mus. Hist. Nat., Montevideo, vol. 4, no 48 (1969), pp. 1-5.

(15) Osorio, H. S.: "Contributions to the lichen flora of Argentina, XIII: Lichens from Misiones Province". Comunic. Bot. Mus. Hist. Nat., Montevideo, vol. 4, no 63 (1981), pp. 1-18.

(16) Osorio, H. S.: "Contributions to the lichen flora of Uruguay, VII: A preliminary catalogue". Comunic. Bot. Mus. Hist. Nat., Montevideo, vol. 4, no 56 (1972), pp. 1-46.

(17) Osorio, H. S.: "Contributions to the lichen flora of Uruguay, VIII. Additions and corrections". Comunic. Bot. Mus. Hist. Nat., Montevideo, vol. 4, no 59 (1975), pp. 1-12.

(18) Osorio, H. S.; Homrich, M. H.: "Contributions to the lichen flora of Brazil IV: Lichens from Southern Rio Grande do Sul". The Bryologist, no 81 (1978), pp. 452- 454. 